\title{
Web-based patient portal use and medication overlap from VA and private-sector pharmacies among older veterans
}

\author{
Kevin T Stroupe, PhD; Kim Nazi, PhD; Timothy P Hogan, PhD; Linda Poggensee, MS; Bonnie Wakefield, PhD; \\ Rachael N Martinez, PhD; Bella Etingen, PhD; Stephanie Shimada, PhD; Katie J Suda, PharmD, MS, FCCP; \\ Zhiping Huo, MS; Lishan Cao, MS; and Bridget M Smith, PhD
}

\section{What is already known about this subject}

- Health care providers and patients have previously reported that use of personal health portal features such as the Blue Button feature of the Department of Veterans Affairs (VA) My HealtheVet patient portal can improve aspects of care coordination; however, effects on medication use are unknown.

\section{What this study adds}

- This study found that veterans using the Blue Button medication view feature of the My HealtheVet patient portal received more medications from VA pharmacies.

- Among veterans receiving larger numbers of medications, use of the Blue Button medication view feature of the My HealtheVet patient portal was associated with less acquisition of similar medications from VA and community-based pharmacies reimbursed by the Medicare Part D prescription drug benefit.

\section{ABSTRACT}

BACKGROUND: The availability of Medicare Part D pharmacy coverage may increase veterans' options for obtaining medications outside of the Department of Veterans Affairs (VA) pharmacies. However, availability of

\section{Author affiliations}

Kevin T Stroupe, PhD, Center of Innovation for Complex Chronic Healthcare (CINCCH), Edward Hines Jr. VA Hospital, US Department of Veterans Affairs, Hines, IL, and Department of Public Health Sciences, Loyola University Chicago, Maywood, IL. Kim Nazi, PhD, Independent Consultant, Veterans and Consumers Health Informatics Office, Office of Connected Care, Veterans Health Administration, US Department of Veterans Affairs, Coxsackie, NY. Timothy P Hogan, $\mathrm{PhD}$, Center for Healthcare Organization and Implementation Research (CHOIR), Edith Nourse Rogers Memorial Veterans Hospital, US Department of Veterans Affairs, Bedford, MA, and Department of Population and Data Sciences, University of Texas Southwestern Medical Center, Dallas, TX. Linda Poggensee, MS; Rachael N Martinez, PhD; Bella Etingen, PhD; Zhiping Huo, MS; and Lishan Cao, MS, Center of Innovation for Complex Chronic Healthcare (CINCCH), Edward Hines Jr. VA Hospital, US Department of Veterans Affairs, Hines, IL. Bonnie Wakefield, PhD, Center for Access and Delivery Research and Evaluation, lowa City Veterans Affairs Healthcare System, lowa City, IA, and Sinclair School of Nursing, University of

Part D coverage raises the potential that veterans may be receiving similar medications from VA and non-VA pharmacies. The VA's personal health record portal, My HealtheVet, allows veterans to self-enter the non-VA medications that they obtained from community-based pharmacies, including
Missouri, Columbia. Stephanie Shimada, PhD, Center for Healthcare Organization and Implementation Research (CHOIR), Edith Nourse Rogers Memorial Veterans Hospital, US Department of Veterans Affairs, Bedford, MA, and Department of Health Law, Policy, and Management, Boston University School of Public Health, Boston, MA. Katie J Suda, PharmD, MS, FCCP, Center for Health Equity Research and Promotion, VA Pittsburgh Healthcare System, Pittsburgh, PA, and Division of General Internal Medicine, University of Pittsburgh School of Medicine, Pittsburgh, PA. Bridget M Smith, PhD, Center of Innovation for Complex Chronic Healthcare (CINCCH), Edward Hines Jr. VA Hospital, US Department of Veterans Affairs, Hines, IL, and Feinberg School of Medicine, Northwestern University, Chicago, IL.

\section{AUTHOR CORRESPONDENCE:}

Kevin T Stroupe, 708.202.3557;

kevin.stroupe@va.gov

J Manag Care Spec Pharm. 2021;27(8):983-94

Copyright (C)2021, Academy of Managed Care Pharmacy. All rights reserved.

those reimbursed by Medicare Part D. The Blue Button medication view feature of My HealtheVet allows veterans to view and download their VA and self-entered non-VA medication history.

OBJECTIVE: To examine whether the use by veterans of the Blue Button feature of My 
HealtheVet was associated with less acquisition of similar medications from VA and community-based pharmacies reimbursed by Medicare Part D.

METHODS: This study included a national sample of veterans who were new My HealtheVet users during fiscal year 2013 (October 1, 2012-September 30, 2013) and who used the Blue Button medication view feature of My HealtheVet at least once (users). We compared these veterans with a random sample of veterans who were not registered to use My HealtheVet (nonusers). From these groups, we identified veterans who were enrolled in Part D. We used multiple logistic regression analysis to assess the association of Blue Button medication view use with obtaining medications from the same drug classes (with overlap of 7 or more days) from VA and Part D-reimbursed pharmacies.

RESULTS: There were 7,973 My HealtheVet medication view users and 65,985 nonusers. During a 12 -month period, medication view users received more 30-day supplies of medications (one 90-day supply equals three 30 -day supplies) than nonusers, on average (152.1 vs 71.3, $P<0.001$ ). A larger percentage of users than nonusers obtained medications from VA and Part D-reimbursed pharmacies with overlapping days supply from the same drug classes (30\% vs $23 \%, P<0.001)$. However, for veterans who obtained greater numbers of 30-day supplies ( 82 or more), a significantly smaller percentage of users than nonusers obtained overlapping medications from VA and Part D-reimbursed pharmacies. Moreover, controlling for the total number of 30-day supplies that veterans received, the odds of obtaining medications from VA and Part D-reimbursed pharmacies with days supply that overlapped by at least 7 days for the same drug classes was $18 \%$ lower for users than nonusers $(P=0.002)$.

CONCLUSIONS: Veterans who used the Blue Button medication view feature of My HealtheVet obtained a larger number of 30-day supplies of medications from VA pharmacies than nonusers. For veterans who obtained a larger number of 30-day supplies of medications, use of the Blue Button medication view feature of My HealtheVet was associated with less overlap in days supply of medication from the same drug class from VA and Part D-reimbursed pharmacies.

Approximately $13 \%$ of all adults in the United States are veterans, including over $50 \%$ of men who meet Medicare's age requirement ( $\geq 65$ years). ${ }^{1}$ Moreover, $46.8 \%$ of the US veteran population (over 9.1 million veterans) are enrolled in or use Department of Veterans Affairs (VA) health care. ${ }^{2}$ Veterans who receive care at VA health care facilities may obtain prescription medications from VA pharmacies. Many of these veterans have complex health care needs because they have multiple chronic conditions, need highly specialized care, and receive health care from VA and non-VA providers. ${ }^{3-6}$ Consequently, many of these veterans may be receiving medications from VA and non-VA prescribers. The US
Medicare system is a national health insurance program for individuals who meet the age requirement, have a disability, or have end-stage kidney disease. For veterans who meet 1 or more of these requirements, non-VA care may be covered by the Medicare insurance program. In the Medicare system, Medicare Part D is an optional federal government program, which went into effect in January 2006 to create an outpatient prescription drug benefit to help Medicare beneficiaries, including veterans who are also receiving care at VA health care facilities, pay for self-administered prescription drugs. The availability of the Medicare Part D prescription drug benefit may facilitate access to non-VA medications. In 2018, the Survey of Veteran Enrollees' Health and Use of Health Care estimated that approximately 17\% of veterans enrolled in VA health care were also enrolled in Medicare Part D.?

The availability of Medicare Part D prescription drug coverage may increase options for veterans to obtain medications. For example, VA users who are enrolled in Medicare may be receiving medications from non-VA prescribers that are reimbursed under Medicare Part D because of recent stays at non-VA hospitals, preferences for specialty care outside the VA, or closer proximity of non-VA providers to their homes. This additional source of coverage raises the potential that veterans may be receiving similar medications from VA and non-VA pharmacies. If veterans are treated by multiple VA and non-VA prescribers with limited information sharing, the VA's ability to limit possible duplication of therapy and prevent untoward consequences of polypharmacy might be inhibited. ${ }^{8}$

Online personal health record portals such as the VA's My HealtheVet portal have tremendous potential to support access and organization of information about an individual's health, ${ }^{9-11}$ including information sharing with their health care providers about their medications. ${ }^{12}$ Veterans can access the My HealtheVet portal and use its various features through multiple platforms, including web browsers accessed on a computer, tablet, or smartphone. The Blue Button feature in the portal enables veterans to access and download a copy of their VA health records into a text, PDF, or XML file that can be read, printed, or saved and then shared with health care providers..$^{13,14}$ The Blue Button medication view feature provides access to information about the prescriptions processed by VA pharmacies in the previous 15 months and all medications self-entered into My HealtheVet by the veteran. ${ }^{15}$

Health care providers and patients have previously reported that use of personal health portal features such as Blue Button can improve aspects of care coordination. ${ }^{16,17}$ However, other pilot randomized controlled trials of Blue Button that have compared the medical records of providers 
who care for veterans receiving VA and community-based care did not reveal improvements in medication reconciliation. ${ }^{18}$ Whether use of personal health record features such as Blue Button is associated with decreased acquisition of similar medications from multiple health care systems remains unknown.

In this study, we examined whether veterans' use of the Blue Button medication view feature of the My HealtheVet patient portal was associated with less acquisition of similar medications from VA and community-based pharmacies reimbursed by the Medicare Part D prescription drug benefit.

\section{Methods}

\section{STUDY DESIGN}

Data were collected as part of a retrospective analysis that examined My HealtheVet use among veterans receiving VA health care, including effects on VA health care use and dual use of services from VA and community providers reimbursed by Medicare. The focus of this analysis was the association of My HealtheVet use with acquisition of similar medications from VA and community pharmacies. The study included a national sample of veterans who were newly authenticated users of My HealtheVet during fiscal year 2013 (October 1, 2012-September 30, 2013) and who used the Blue Button medication view feature at least once (users). We compared these Blue Button users with a random sample of veterans who were not registered to use My HealtheVet (nonusers; Supplementary Figure 1, available in online article).

From these 2 groups, we identified veterans who were also enrolled in Medicare Part D for at least 1 month following the index date. Veterans who were deceased, aged younger than 18 years or older than 104 years, or missing data on variables included as covariates in adjusted models (eg, distance to nearest VA, region of residence, urban residence, and VA enrollment priority group) were excluded from the sample. For veterans who used the My HealtheVet Blue Button medication view feature, the index date was defined as the date of the first use of this feature. For nonusers of My HealtheVet, the index date was July 1, 2013. The mean number of months on Medicare Part D was 9.5 for veterans in the medication view user group and 10.8 in the My HealtheVet nonuser group during the 12-month period following the index date. This study was approved by the Institutional Review Board at the Edward Hines, Jr. VA Hospital.

\section{MEASURES AND DATA SOURCES}

Medication Acquisition from VA and Community Pharmacies. Medication acquisition was assessed during the 12-month period following the index date. We obtained data from the VA Managerial Cost Accounting (MCA) National Data Extract (NDE) Pharmacy datasets and the Medicare Part D "Slim" file. ${ }^{19}$ The Centers for Medicare \& Medicaid Services (CMS) requires that insurance companies submit data to CMS on all prescriptions that have been dispensed and paid through the Part D program. These prescriptions are recorded in the Prescription Drug Event file. The Part D Slim file contains a subset of variables from this file that are of particular interest to researchers (eg, prescription service date, product, quantity dispensed, and days supply).

Medication acquisition was measured as the number of 30-day medication supplies (eg, one 90-day supply was equivalent to three 30-day supplies) and the number of different drug classes that veterans received from VA and Part D-reimbursed pharmacies. The drug classes were based on the VA Drug Classification system, which separates drugs, supplies, and diagnostics into different categories based on their characteristics. Drug classes in this system may vary in their level of specificity; however, this classification system provides general categories of drugs and mostly follows the American Hospital Formulary Service drug classifications.

For medications from VA pharmacies, the VA drug classes were obtained from the VA MCA NDEs. To assign VA drug classes to medications in the Part D Slim file, we linked records in this file with the VA's National Drug File using National Drug Code numbers. The VA National Drug File contains product-level information about medications dispensed by VA pharmacies such as the product's National Drug Code number and VA drug class. To assess whether veterans obtained similar medications from VA and community-based pharmacies, we determined the percentage of veterans who received medications from the same drug class with overlapping days supply from VA and community-based pharmacies reimbursed by the Medicare Part D drug benefit.

Data for medications from the community-based pharmacies that we used to assess overlapping days supply was obtained from the Medicare Part D Slim file. Overlap of medication supplies from VA or community-based pharmacies of 7 days or more was operationalized dichotomously (ie, each veteran either had or did not have this overlap).

Demographics. Characteristics were assessed during the 12-month period after the index date. Information about 


\section{TABLE 1 Patient Characteristics}

\begin{tabular}{|c|c|c|c|c|c|c|}
\hline & \multicolumn{3}{|c|}{ Unweighted } & \multicolumn{3}{|c|}{ Weighted } \\
\hline & $\begin{array}{c}\text { Blue Button } \\
\text { medication } \\
\text { view users } \\
n=7,973\end{array}$ & $\begin{array}{c}\text { My HealtheVet } \\
\text { nonusers } \\
n=65,985\end{array}$ & Std. diff. & $\begin{array}{c}\text { Blue Button } \\
\text { medication } \\
\text { view users } \\
n=7,973\end{array}$ & $\begin{array}{c}\text { My HealtheVet } \\
\text { nonusers } \\
n=65,985\end{array}$ & Std. diff. \\
\hline Age, year, mean & 67.9 & 74.7 & -0.97 & 74.1 & 74.1 & 0.001 \\
\hline \multicolumn{7}{|l|}{ Sex, \% } \\
\hline Male & 96.3 & 98.0 & -0.10 & 97.5 & 97.8 & -0.02 \\
\hline Female & 3.7 & 2.0 & 0.10 & 2.5 & 2.2 & 0.02 \\
\hline \multicolumn{7}{|l|}{ Race, \% } \\
\hline White & 90.0 & 84.2 & 0.18 & 81.0 & 84.2 & -0.10 \\
\hline Black & 8.2 & 13.6 & -0.17 & 16.8 & 13.0 & 0.10 \\
\hline Other & 1.8 & 2.3 & -0.04 & 2.3 & 2.3 & 0.0004 \\
\hline \multicolumn{7}{|l|}{ Region, \% } \\
\hline Midwest & 23.0 & 24.1 & -0.03 & 21.4 & 23.8 & -0.06 \\
\hline Northeast & 14.7 & 18.6 & -0.11 & 15.9 & 18.2 & -0.06 \\
\hline South & 40.5 & 35.9 & 0.09 & 38.7 & 36.5 & 0.04 \\
\hline West & 20.0 & 17.8 & 0.06 & 19.1 & 18.0 & 0.03 \\
\hline Other & 1.8 & 3.7 & -0.11 & 4.8 & 3.5 & 0.07 \\
\hline \multicolumn{7}{|l|}{ Rural/urban, \% } \\
\hline Rural & 35.6 & 36.6 & -0.02 & 36.6 & 36.5 & 0.002 \\
\hline Urban & 63.8 & 62.0 & 0.04 & 62.0 & 62.1 & -0.001 \\
\hline Missing & 0.6 & 1.5 & -0.09 & 1.4 & 1.4 & -0.003 \\
\hline \multicolumn{7}{|c|}{ Distance to nearest VA hospital, \% } \\
\hline $0-4$ miles & 6.9 & 8.4 & -0.05 & 9.8 & 8.1 & 0.06 \\
\hline 5-19 miles & 36.2 & 32.4 & 0.08 & 31.1 & 32.9 & -0.04 \\
\hline 20-39 miles & 25.2 & 27.1 & 0.04 & 23.1 & 25.3 & -0.05 \\
\hline 40-59 miles & 13.9 & 15.1 & -0.03 & 17.7 & 14.9 & 0.08 \\
\hline $60+$ miles & 15.2 & 17.5 & -0.06 & 16.9 & 17.3 & -0.01 \\
\hline Missing & 0.7 & 1.5 & -0.08 & 1.5 & 1.5 & -0.0001 \\
\hline
\end{tabular}

veterans' characteristics were obtained from the VA Medical SAS Databases and included sex, age, race, ethnicity, and US geographic region of residence (ie, Midwest, Northeast, South, West, and other). ${ }^{20}$ The distance between the nearest VA facility to the veteran and the center of the ZIP code associated with the veteran's address was used to estimate distance to the nearest VA. A veteran's VA enrollment group, a classification system used to determine copayments for VA services based on disability rating, income, and other factors (eg, prisoner of war status), was determined using the VA Enrollment file. The socioeconomic status of the veteran's geographic area was estimated using data on the median household income in the veteran's county of residence from the Area Health Resources Files. ZIP code information was used to determine the urbanicity of the veteran's residence. ${ }^{21}$ Overall health status was estimated through the CMS Hierarchical Condition Category (HCC) risk-adjustment model for community-dwelling populations..$^{22,23}$

My HealtheVet Registration and Blue Button Use. Registration for My HealtheVet and use of the Blue Button medication view feature were obtained from VA My HealtheVet usage data. 


\section{TABLE 1 Patient Characteristics (continued)}

\begin{tabular}{|c|c|c|c|c|c|c|}
\hline & \multicolumn{3}{|c|}{ Unweighted } & \multicolumn{3}{|c|}{ Weighted } \\
\hline & $\begin{array}{c}\text { Blue Button } \\
\text { medication } \\
\text { view users } \\
n=7,973\end{array}$ & $\begin{array}{c}\text { My HealtheVet } \\
\text { nonusers } \\
n=65,985\end{array}$ & Std. diff. & $\begin{array}{c}\text { Blue Button } \\
\text { medication } \\
\text { view users } \\
n=7,973\end{array}$ & $\begin{array}{c}\text { My HealtheVet } \\
\text { nonusers } \\
n=65,985\end{array}$ & Std. diff. \\
\hline \multicolumn{7}{|c|}{ Distance to nearest Medicare-reimbursed hospital } \\
\hline $0-4$ miles & 38.5 & 40.2 & -0.04 & 41.8 & 39.9 & 0.04 \\
\hline 5-19 miles & 55.9 & 52.8 & 0.06 & 49.3 & 53.2 & -0.08 \\
\hline 20-39 miles & 4.4 & 5.0 & -0.03 & 6.7 & 5.0 & 0.07 \\
\hline 40-59 miles & 0.4 & 0.4 & 0.002 & 0.7 & 0.4 & 0.04 \\
\hline $60+$ miles & 0.1 & 0.07 & 0.0004 & 0.1 & 0.1 & -0.01 \\
\hline Missing & 0.7 & 1.5 & -0.08 & 1.5 & 1.5 & -0.0001 \\
\hline \multicolumn{7}{|c|}{ Enrollment priority group, \%a } \\
\hline Group 1 & 28.9 & 14.0 & 0.37 & 17.1 & 15.4 & 0.05 \\
\hline Group 2 & 54.0 & 55.0 & -0.02 & 55.6 & 55.0 & 0.01 \\
\hline Group 3 & 17.1 & 31.1 & -0.33 & 27.3 & 29.6 & -0.05 \\
\hline Married, \% & 68.1 & 58.6 & 0.20 & 52.4 & 59.4 & -0.13 \\
\hline HCC risk score, mean & 0.6 & 0.9 & -0.55 & 0.97 & 0.9 & 0.10 \\
\hline
\end{tabular}

${ }^{a}$ Group 1 =VA enrollment priority group 1 (those with no medication copayments); Group 2 =VA enrollment priority groups 2-6 (those with copayments for medications not related to service-connected conditions and an annual cap on medication copayments); Group 3=VA enrollment priority groups 7-8 (those with copayments for medications not related to service-connected conditions but no annual cap on medication copayments).

HCC = Hierarchical Condition Category; Std. diff.=standardized difference; VA=Department of Veterans Affairs.

\section{STATISTICAL ANALYSIS}

Analyses were conducted using Stata version 14 (StataCorp). To balance characteristics between users and nonusers, we used propensity score weighting. ${ }^{24}$ We calculated the propensity score for each veteran as the predicted probability of using the Blue Button medication view feature from multiple logistic regression analyses of patient characteristics shown in Table 1. Each veteran was assigned a propensity score weight based on this propensity score. For users, the weight was the inverse of the propensity score; for nonusers, the weight was equal to the inverse of 1 minus the propensity score. ${ }^{24}$ We calculated the SDs in characteristics between the groups to ensure that characteristics were similar between comparison groups after weighting.

To examine the types and sources of medications, we assessed the number of 30-day supplies and the number of different medication classes that veterans received from VA, Part D-reimbursed, or both types of pharmacies. We compared these between users and nonusers. We also examined how medication acquisition was distributed between VA and Part D-reimbursed pharmacies. Additionally, for all pharmacy use groups, we examined the most frequently occurring drug classes for which the days supply of medications from VA or Part D-reimbursed pharmacies overlapped by 7 or more days, a time period used previously to assess medication overlap. ${ }^{25}$

To assess the association of Blue Button medication view use with obtaining medications from VA and communitybased pharmacies with days supply from the same drug class that had overlap by 7 or more days, we used multivariable logistic regression analysis with double-robust estimation. ${ }^{26}$ We assessed whether a veteran had an overlap of medication supplies from VA or community-based pharmacies of 7 days or more as a dichotomous variable (ie, each veteran either had or did not have this overlap).

With double-robust estimation, the logistic regression model included covariates and was estimated with inverse probability weighting as previously described. Results will be unbiased with double-robust estimation if either the propensity score or outcome (in this case logistic regression) model are specified correctly. ${ }^{26}$ Additionally, we determined the proportion of veterans in each group with 7 or more days supply overlap from the same drug class. We compared these proportions between the user and the nonuser groups overall and by decile of the number of 30-day supplies of medications that veterans obtained. 


\section{TABLE 2 Medication Supplies and Drug Classes}

\begin{tabular}{|c|c|c|c|}
\hline & $\begin{array}{c}\text { Blue Button } \\
\text { medication view users } \\
n=7,973\end{array}$ & $\begin{array}{c}\text { My HealtheVet } \\
\text { nonusers } \\
n=65,985\end{array}$ & $P$ value \\
\hline \multicolumn{4}{|l|}{ 30-day supplies } \\
\hline Number from VA pharmacies, mean (SD) & $135.3(108.4)$ & $41.9 \quad(46.6)$ & $<0.001$ \\
\hline Number from Part D-reimbursed pharmacies, mean (SD) & $16.8 \quad(26.4)$ & $(37.1)$ & $<0.001$ \\
\hline Total number, mean (SD) & $152.1(106.0)$ & $(49.1)$ & $<0.001$ \\
\hline Reliance on VA pharmacies, $\%$ & & & $<0.001$ \\
\hline $0 \%$ of 30 -day supplies from VA pharmacies & 3.2 & 21.3 & \\
\hline $1 \%-20 \%$ of 30 -day supplies from VA pharmacies & 2.6 & 10.3 & \\
\hline $20 \%-40 \%$ of 30 -day supplies from VA pharmacies & 4.2 & 8.4 & \\
\hline $40 \%-60 \%$ of 30 -day supplies from VA pharmacies & 6.1 & 8.2 & \\
\hline $60 \%-80 \%$ of 30 -day supplies from VA pharmacies & 10.3 & 9.9 & \\
\hline $80 \%-99 \%$ of 30 -day supplies from VA pharmacies & 40.8 & 17.5 & \\
\hline $100 \%$ of 30 -day supplies from VA pharmacies & 32.7 & 24.5 & \\
\hline \multicolumn{4}{|l|}{ Drug classes } \\
\hline Number from VA pharmacies, mean (SD) & $(6.3)$ & $(5.6)$ & $<0.001$ \\
\hline Number from Part D-reimbursed pharmacies, mean (SD) & $(3.5)$ & $(4.9)$ & $<0.001$ \\
\hline Both VA and Part D-reimbursed pharmacies, mean (SD) & $(1.6)$ & $(1.8)$ & $<0.001$ \\
\hline Total number of drug classes, mean (SD) & $(6.5)$ & $(6.0)$ & $<0.001$ \\
\hline
\end{tabular}

\section{Results}

There were 73,958 veterans who met the study inclusion and exclusion criteria: 7,973 were Blue Button medication view users, and 65,985 were nonusers. Table 1 presents patient characteristics before and after propensity score weighting. Before weighting, there were imbalances (ie, SDs >0.1) between groups (eg, age, race, enrollment priority group, and HCC risk score). After propensity score weighting, these imbalances were reduced.

\section{PATTERNS OF MEDICATION ACQUISITION}

During the 12-month period following the index date, users obtained on average (SD) 135.3 (108.4) 30-day supplies of medications from VA pharmacies, whereas nonusers obtained on average 41.9 (46.6) 30-day supplies of medications from VA pharmacies $(P<0.001$; Table 2$)$. Fewer supplies of medications were from non-VA pharmacies, and Blue Button medication view users received, on average (SD), 16.8 (26.4) 30-day supplies of medications from Medicare Part D-reimbursed pharmacies; nonusers obtained on average 29.4 (37.1) from Part D-reimbursed pharmacies
$(\mathrm{P}<0.001)$. Combining VA and Medicare Part D-reimbursed pharmacies, users obtained on average (SD) 152.1 (106.0) total 30-day medication supplies; nonusers obtained, on average, 71.3 (49.1) total 30-day supplies $(\mathrm{P}<0.001)$.

Users tended to rely on the VA for a substantial percentage of their medication acquisition. Over 73\% of users obtained $80 \%$ or more of their 30 -day supplies of medications from VA pharmacies; only $5.8 \%$ of users received $20 \%$ or less of their 30-day supplies of medications from VA pharmacies. In contrast, $42 \%$ of nonusers obtained $80 \%$ or more of their 30-day supplies of medications from VA pharmacies, and $31.6 \%$ of nonusers received $20 \%$ or less of their medication supplies from VA pharmacies (Table 2).

Users obtained medications from an average (SD) of 12.0 (6.3) different VA drug classes. On average, 69.2\% of these classes $(8.3 / 12)$ were from VA pharmacies only; 22.5\% (2.7/12) were from Part D-reimbursed pharmacies only; and $6.7 \%(0.8 / 12)$ classes were from both VA and Part D-reimbursed pharmacies (Table 2). In comparison, nonusers obtained medications from an average (SD) of 10.4 (6.0) different drug classes $(\mathrm{P}<0.001)$. On average, 


\section{FIGURE 1 Percentage of Veterans Who Received Medications from VA Pharmacies and Medicare Part D-Reimbursed Pharmacies With Days Supply From Same Drug Classes That Overlapped by $\geq 7$ Days Stratified by Number of 30-Day Supplies of Medications}

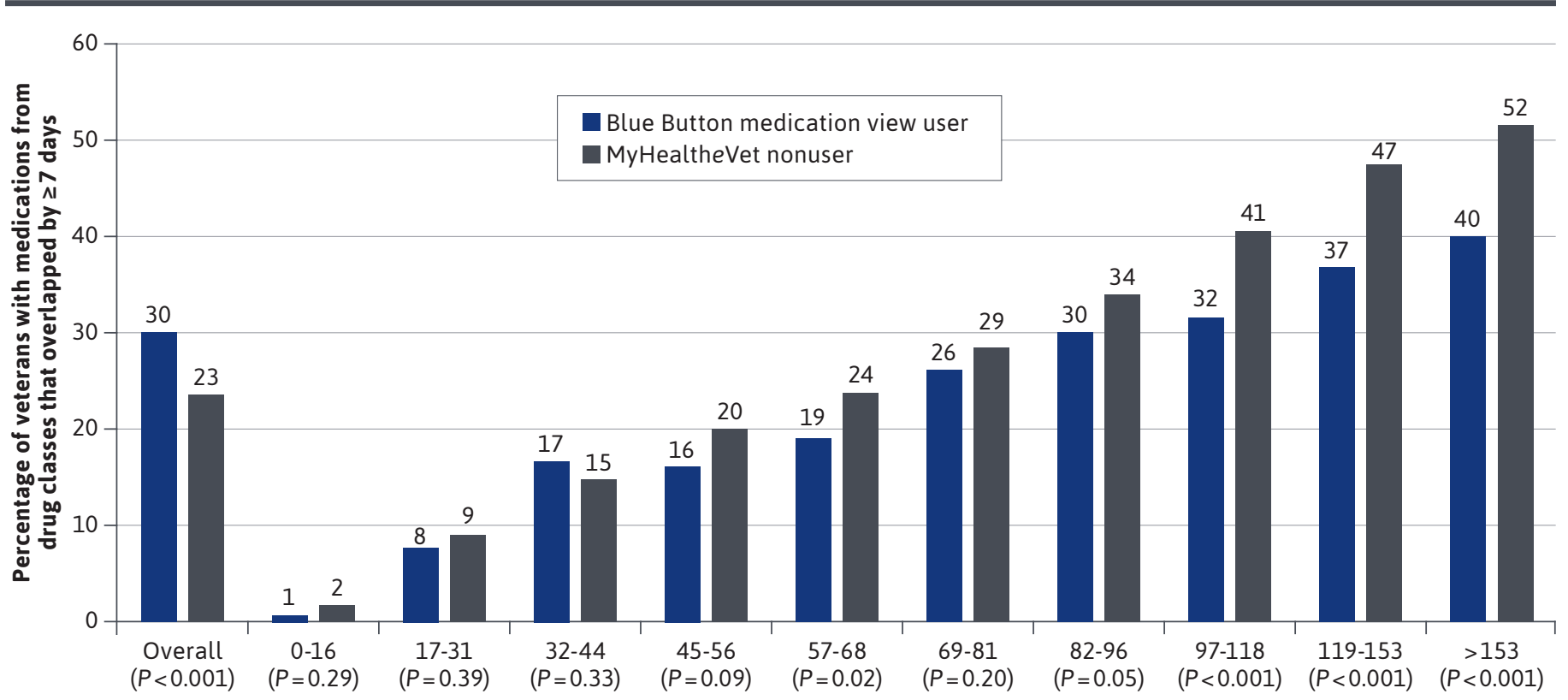

Number of 30-day supplies of medications received

$49.0 \%$ of these classes $(5.1 / 10.4)$ were from VA pharmacies only; 43.3\% (4.5/10.4) were from non-VA pharmacies only; and $9.6 \%(1.0 / 10.4)$ classes were from both VA and non-VA pharmacies.

\section{MEDICATION OVERLAP}

Figure1 presents the percentage of veterans with overlapping days supply of drug classes from VA and Part D-reimbursed pharmacies. Overall, a larger percentage of veterans in the Blue Button medication view user group had overlapping medications (30\% vs 23\%, P<0.001). However, the percentage of patients with overlap varied by the total number of 30-day supplies of medications that a veteran obtained. In Figure 1, the percentage of veterans with overlapping days supply is stratified by the number of 30-day supplies of medications that veterans obtained (in deciles). Among those obtaining high numbers of 30-day supplies of medications, the percentage of veterans with overlapping days supply was significantly lower for Blue Button medication view users than for nonusers.

For veterans with 82-96 thirty-day supplies, the percentage of users with overlapping days supply of medication was 4 percentage points lower than for nonusers (30\% vs $34 \%, P=0.05)$; for veterans with more than 153 thirty-day supplies, the percentage of users with overlapping days supply of medication was 12 percentage points lower than for nonusers (40\% vs 52\%, $\mathrm{P}<0.001)$.

Results from the double-robust estimation in Table 3 were consistent with the results above. The odds of having overlap in the days supply from both VA and Part D-reimbursed pharmacies of 7 or more days was 18\% lower for users than nonusers (odds ratio $[\mathrm{OR}]=0.82 ; 95 \% \mathrm{CI}=0.72-0.93$; $\mathrm{P}=0.002$ ), controlling for the number of 30-day supplies of medications that veterans received. Other characteristics associated with greater odds of having overlapping days supply of drug classes from VA and Part D-reimbursed pharmacies included age more than 45 years, living in an urban area, living further from a VA facility, and obtaining a larger number of 30-day supplies from VA pharmacies.

The top drug classes for which the days supply from VA and non-VA pharmacies overlapped by 7 or more days are presented in Table 4. Of note, opioid analgesics were among the top 10 drug classes for which there was overlap in the days supply from both VA and non-VA pharmacies. 


\section{TABLE 3 Characteristics Associated with Medication Overlap}

\begin{tabular}{|c|c|c|c|}
\hline & OR & $95 \% \mathrm{Cl}$ & $P$ value \\
\hline Blue Button medication view users & 0.82 & $0.72-0.93$ & 0.002 \\
\hline \multicolumn{4}{|l|}{ Age, years } \\
\hline$\leq 45$ & Reference & & \\
\hline$>45$ to $\leq 65$ & 1.59 & $1.04-2.44$ & 0.032 \\
\hline$>65$ to $\leq 75$ & 1.62 & $1.06-2.46$ & 0.024 \\
\hline$>75$ to $\leq 85$ & 1.96 & $1.26-3.06$ & 0.003 \\
\hline$>85$ & 2.27 & $1.43-3.62$ & 0.001 \\
\hline Female & 0.99 & $0.76-1.29$ & 0.97 \\
\hline \multicolumn{4}{|l|}{ Race } \\
\hline White & Reference & & \\
\hline Black & 0.79 & $0.63-1.00$ & 0.05 \\
\hline Other & 1.13 & $0.81-1.56$ & 0.48 \\
\hline \multicolumn{4}{|l|}{ Region } \\
\hline Midwest & Reference & & \\
\hline Northeast & 1.14 & $0.93-1.41$ & 0.22 \\
\hline South & 1.23 & $1.05-1.45$ & 0.01 \\
\hline West & 1.13 & $0.91-1.40$ & 0.27 \\
\hline Other & 1.50 & $0.94-2.38$ & 0.09 \\
\hline
\end{tabular}

Rural/urban

\begin{tabular}{l|c|c|c}
\hline Rural & Reference & & \\
\hline Urban & 1.28 & $1.08-1.53$ & 0.01 \\
\hline Missing & 2.17 & $0.77-6.06$ & 0.14
\end{tabular}

Distance to nearest VA hospital

\begin{tabular}{l|c|c|c}
\hline $0-4$ miles & Reference & & \\
\hline $5-19$ miles & 1.31 & $1.02-1.69$ & 0.04 \\
\hline $20-39$ miles & 1.19 & $0.91-1.54$ & 0.21 \\
\hline $40-59$ miles & 1.52 & $1.12-2.06$ & 0.01 \\
\hline $60+$ miles & 1.78 & $1.28-1.49$ & 0.001 \\
\hline Missing & 0.62 & $0.26-1.49$ & 0.28 \\
\hline
\end{tabular}

\section{Distance to nearest Medicare hospital}

\begin{tabular}{l|c|c|c}
\hline $0-4$ miles & Reference & & \\
\hline $5-19$ miles & 1.06 & $0.89-1.26$ & 0.53 \\
\hline $20-39$ miles & 1.05 & $0.71-1.56$ & 0.82 \\
\hline $40-59$ miles & 0.31 & $0.09-1.11$ & 0.07 \\
\hline $60+$ miles & 1.32 & $0.61-2.87$ & 0.49 \\
\hline VA enrollment priority group ${ }^{a}$
\end{tabular}

VA enrollment priority group ${ }^{a}$

\begin{tabular}{l|c|c|c}
\hline Group 1 & Reference & & \\
\hline Group 2 & 1.02 & $0.89-1.16$ & 0.79 \\
\hline Group 3 & 1.11 & $0.93-1.33$ & 0.25 \\
\hline Married & 1.14 & $0.99-1.33$ & 0.07 \\
\hline
\end{tabular}

continued on next page

\section{Discussion}

Veterans who were using the Blue Button medication view feature of the VA's personal health record portal My HealtheVet obtained over 3 times the number of 30-day supplies of medications from VA pharmacies and over twice the number of total 30-day supplies from all sources (ie, VA and Part D-reimbursed pharmacies) as nonusers. Nearly a third of users and nearly a quarter of nonusers obtained prescriptions with overlapping days supply of 7 or more days for medications from the same drug classes from both VA and Part D-reimbursed pharmacies. Although the overall percentage of veterans with overlapping days supply was significantly larger for veterans who used the Blue Button medication view feature of My HealtheVet, this was because these users tended to have a higher number of prescriptions to fill.

My HealtheVet's health information management and communication features may be especially attractive to patients who are managing complex chronic diseases, and those managing multiple medications may be more likely to adopt the portal because of the convenience of online prescription refills and the Blue Button medication view feature.

The percentage of veterans with overlapping days supply from the same drug classes varied by the total number of 30-day supplies that veterans obtained. Among veterans with a need for a greater number of 30-day supplies of medications, the percentage with overlapping days supply was lower for veterans who used the Blue Button medication view feature than for nonusers. Moreover, adjusting for the number of medication supplies, the odds of obtaining overlapping days supply was over $18 \%$ lower for users.

These findings highlight that a substantial portion of veterans receive 


\section{TABLE 3}

\begin{tabular}{|c|c|c|c|}
\hline & OR & $95 \% \mathrm{Cl}$ & $P$ value \\
\hline \multicolumn{4}{|c|}{ Quintiles of number of 30-day supplies } \\
\hline 0 & Reference & & \\
\hline 1 & 5.53 & $1.47-20.77$ & 0.01 \\
\hline 2 & 10.23 & $2.78-37.66$ & $<0.001$ \\
\hline 3 & 11.14 & $3.08-40.23$ & $<0.001$ \\
\hline 4 & 13.27 & $3.66-48.15$ & $<0.001$ \\
\hline 5 & 22.74 & $6.31-81.94$ & $<0.001$ \\
\hline 6 & 27.32 & $7.60-98.23$ & $<0.001$ \\
\hline 7 & 32.47 & $9.07-116.16$ & $<0.001$ \\
\hline 8 & 41.74 & $11.62-150.00$ & $<0.001$ \\
\hline 9 & 52.22 & $14.47-188.47$ & $<0.001$ \\
\hline \multicolumn{4}{|c|}{ Quartiles of HCC risk scores } \\
\hline 0 & Reference & & \\
\hline 1 & 0.83 & $0.71-0.96$ & 0.02 \\
\hline 2 & 0.89 & $0.77-1.03$ & 0.12 \\
\hline 3 & 0.82 & $0.69-0.97$ & 0.02 \\
\hline
\end{tabular}

${ }^{a}$ Group $1=$ VA enrollment priority group 1 (those with no medication copayments); Group 2 =VA enrollment priority groups 2-6 (those with copayments for medications not related to service-connected conditions and an annual cap on medication copayments); Group 3=VA enrollment priority groups 7-8 (those with those with copayments for medications not related to service-connected conditions but no annual cap on medication copayments).

$H C C=$ Hierarchical Condition Category; $O R=$ odds ratio; $V A=$ Department of Veterans Affairs

medications with overlapping days supply from the same drug classes from both VA and non-VA pharmacies. However, among higher medication users, use of the Blue Button medication view feature of the VA's personal health record portal was associated with less polypharmacy compared with veterans who had not signed up to use the VA's personal record portal. Consequently, it might be useful for prescribers to encourage their patients who are obtaining larger numbers of medications to use the Blue Button medication view feature of My HealtheVet to assist with management of their prescription medications.

For patients acquiring their medications from VA and non-VA pharmacies, the VA may have limited information of the patients' non-VA medications. Efforts are underway to enhance information sharing across VA and non-VA settings ${ }^{27,28}$; however, patients remain the most important source of information about all medications that they are taking. This necessitates additional investigation and communication between providers and patients to ensure optimal medication reconciliation and continuity of care.

This communication is particularly important because situations in which providers in one health care system do not know about medications prescribed by providers in another health care system may pose a safety risk, which is compounded by this study's finding that some of the medications with overlapping days supply from VA and Part D-reimbursed pharmacies are drugs that can be dangerous if not used correctly. For example, among the 10 most frequent drug classes with overlapping days supply are opioid analgesics for which patients are at high risk of death secondary to opioid overdose.

There is limited information on medication reconciliation across health systems. One review suggests that medication reconciliation within health systems has the potential to identify many medication discrepancies and reduce potential harm. ${ }^{29}$ Use of the Blue Button medication view feature of the personal health record portal may enhance medication reconciliation and information sharing across health care systems, which may be warranted, since multiple previous studies have shown possible associations between dual health system use among veterans and increased morbidity and mortality. ${ }^{30-33}$ It should be noted that the Blue Button medication view includes only VA prescriptions and the non-VA medications that veterans self-enter into their personal health records, which may differ from the non-VA medication list in the VA's electronic medical record. However, efforts are underway to make the non-VA medication list available in the patient portal too.

Results from previous studies assessing the potential for My HealtheVet to decrease duplication of services suggest that use of the Blue Button medication view feature might facilitate information sharing across health care systems. In an interventional study, $90 \%$ of providers stated that the Continuity of Care document-a standardized electronic file containing a VA health summary report that patients can share with health care providers available through the Blue Button feature of My HealtheVet-increased their ability 


\section{TABLE 4 Overlap in Drug Classes from VA and Medicare Part D-Reimbursed Pharmacies}

\begin{tabular}{l|l|lll}
\hline & \multicolumn{1}{|c|}{$\begin{array}{c}\text { Blue Button } \\
\text { medication } \\
\text { view users } \\
\mathbf{n = 7 , 9 7 3}\end{array}$} & $\begin{array}{c}\text { My } \\
\text { HealtheVet } \\
\text { nonusers } \\
\mathbf{n = 6 5 , 9 8 5}\end{array}$ \\
\hline Drug class with overlap $\geq 7$ days, \% (n)[rank] & $2.5(203)$ & {$[7]$} & $2.4(1,570)$ & {$[5]$} \\
\hline ACE inhibitors & $2.5(203)$ & {$[6]$} & $2.3(1,514)$ & {$[6]$} \\
\hline Alpha blockers/related & $2.5(197)$ & {$[9]$} & $1.7(1,124)$ & {$[10]$} \\
\hline Anticonvulsants & $4.0(315)$ & {$[3]$} & $2.1(1,381)$ & {$[7]$} \\
\hline Antidepressants, other & $6.4(507)$ & {$[1]$} & $5.0(3,272)$ & {$[1]$} \\
\hline Antilipemic agents & $4.0(316)$ & {$[2]$} & $3.3(2,199)$ & {$[2]$} \\
\hline Beta blockers/related & $2.4(192)$ & {$[10]$} & $2.0(1,343)$ & {$[8]$} \\
\hline Calcium channel blockers & $3.3(262)$ & {$[5]$} & $2.6(1,727)$ & {$[3]$} \\
\hline Gastric medications, other & $3.6(287)$ & {$[4]$} & $2.6(1,686)$ & {$[4]$} \\
\hline Oral hypoglycemic agents, oral & $2.5(198)$ & {$[8]$} & $2.0(1,314)$ & {$[9]$} \\
\hline Opioid analgesics & & & \\
\hline ACE =angiotensin-converting enzyme. & & &
\end{tabular}

to have an accurate medication list and assisted in making medication treatment decisions. ${ }^{16}$ Moreover, 50\% reported that they did not order a laboratory test or another procedure because of information in the Continuity of Care document. ${ }^{16}$

In another study (a pilot randomized trial, $\mathrm{N}=52$ ), veterans who were trained to share their Continuity of Care documents with non-VA providers had significantly fewer duplicate laboratory tests than the control group..$^{18}$ Although not all veterans will download health care data and share it with their health care providers, a tool such as the VA Blue Button medication view feature of My HealtheVet may complement provider-mediated health information exchange until health care systems are designed to allow providers in different organizations to access key information, such as medications, across health care systems.

\section{LIMITATIONS}

There were limitations to these analyses. We only examined non-VA pharmacy data for veterans enrolled in Medicare Part D. Private-sector data were not available for medications that were not reimbursed by a Part $\mathrm{D}$ prescription plan. Consequently, our results provide a lower bound estimate of the percentage of VA enrollees who have overlapping medications from VA and non-VA pharmacies.
There may be multiple approaches to assessing misuse of medications. In this study, we focused on a potential issue (ie, overlapping days supply) that could arise when veterans are obtaining medications from VA pharmacies and community-based pharmacies that are covered by the Medicare Part D drug benefit. Additionally, the Blue Button medication view includes VA medications but only non-VA medications that veterans have self-entered into their personal health records. The non-VA medication list in the VA electronic medical record may differ from the Blue Button non-VA medication list. The effect of this potential inconsistency is uncertain.

It should also be noted that ZIP codes were used to determine rural/urban status, but a veteran may have relocated during the study period. We used the HCC risk score to estimate overall health status of veterans; however, this health status may change over time.

There may be different implications from overlapping days supply due to the same drug vs overlap due to a physician-directed change in treatment. However, we were unable to make this source distinction from our data. Moreover, because the viewing of the medication is highly likely to be correlated with other My HealtheVet features (eg, obtaining online prescription refills or having shareable health records), reduced medication overlap could be a result of these services, as well.

Tying polypharmacy to adverse drug events was beyond the scope of this study; however, we recognize that this would be an important topic for future research. In addition, veterans using the Blue Button medication view feature of My HealtheVet may be different from those not using the feature because of unobservable factors (eg, patient engagement in their care, education, and socioeconomic factors). ${ }^{17}$

\section{Conclusions}

Veterans who used the Blue Button medication view feature of My HealtheVet obtained a larger number of 30-day supplies of medications from VA pharmacies than nonusers. For veterans who obtained a larger number of 30-day supplies of medications, use of the Blue Button medication view feature of My HealtheVet was associated with less overlap in days supply of medication from the same drug class from VA and Part D-reimbursed pharmacies than for nonusers. These results highlight the importance of sharing information and the need to educate patients about communicating with VA and non-VA providers about their medications. 


\section{DISCLOSURES}

This study was funded by the Department of Veterans Affairs, Office of Research and Development, Health Services Research and Development Service project IIR 14-041-2. The sponsor provided funding but was not involved in the development of the manuscript. The views expressed in this article are those of the authors and do not necessarily represent the views of the Department of Veterans Affairs or the Health Services Research and Development Service. All authors are employed in some capacity with the Department of Veterans Affairs and have no conflicts of interest to disclose.

\section{REFERENCES}

1. Newport F. In U.S., $24 \%$ of men, $2 \%$ of women are veterans: among men, veteran status is highly related to age. Gallop. November 12, 2012. Accessed July 16, 2015. http://www.gallup.com/poll/158729/ men-women-veterans.aspx

2. US Department of Veterans Affairs. FY 2014-2020 strategic plan. May 31, 2019. Accessed November 20, 2019. https://www.va.gov/oei/docs/VA20182024strategicPlan.pdf

3. Kazis LE, Miller DR, Clark J, et al. Health-related quality of life in patients served by the Department of Veterans Affairs: results from the Veterans Health Study. Arch Intern Med. 1998;158(6):626-32.

4. Lee TA, Shields AE, Vogeli C, et al. Mortality rate in veterans with multiple chronic conditions. J Gen Intern Med. 2007;22(Suppl 3):403-07.

5. Hynes DM, Koelling K, Stroupe K, et al. Veterans' access to and use of Medicare and Veterans Affairs health care. Med Care. 2007;45(3):214-23.

6. Spelman JF, Hunt SC, Seal KH, Burgo-Black AL. Post deployment care for returning combat veterans. J Gen Intern Med. 2012;27(9):1200-09.
7. Wang ZJ, Cidade M, Larsen M, Pearman G, Schimpf M, Dhanireddy P. 2018 survey of veteran enrollees' health and use of health care: data findings report. Contract No: VA24517-C-0178. January 9, 2019. Accessed July 2, 2019. https://www.va.gov/ HEALTHPOLICYPLANNING/SOE2018/20 18EnrolleeDataFindingsReport_9January2 019Final508Compliant.pdf

8. Gellad WF, Zhao X, Thorpe CT, Mor MK, Good CB, Fine MJ. Dual use of Department of Veterans Affairs and Medicare benefits and use of test strips in veterans with type 2 diabetes mellitus. JAMA Inter Med. 2015;175(1):26-34

9. Civan A, Skeels MM, Stolyar A, Pratt W. Personal health information management: consumers' perspectives. AMIA Annu Symp Proc. 2006:156-60.

10. Reed ME, Huang J, Millman A, Graetz I, et al. Portal use among patients with chronic conditions: patientreported care experiences. Med Care. 2019;57(10):809-14.

11. Nazi KM, Turvey CL, Klein DM, Hogan TP. A decade of veteran voices: examining patient portal enhancements through the lens of user-centered design. J Med Internet Res. 2018;20(7):e10413.

12. Agarwal R, Khuntia J. Personal health information and the design of consumer health information technology: background report. Prepared by Insight Policy Research under Contract No. 290-07-10072-1. AHRQ Publication No. 09-0075-EF. June 2009. Accessed June 29, 2021. https://digital.ahrq.gov/sites/ default/files/docs/citation/09-0075-EF. pdf

13. D'Amore JD, Sittig DF, Ness RB. How the Continuity of Care Document can advance medical research and public health. Am J Public Health. 2012;102(5):E1-E4.

14. Hogan TP, Nazi KM, Luger TM, et al. Technology-assisted patient access to clinical information: an evaluation framework for blue button. JMIR Res Protoc. 2014;3(1):e18.
15. My HealtheVet. VA Blue Button user guide. Accessed August 8, 2019. https://www.myhealth. va.gov/documents/25286/25831/ BlueButtonUserGuide-OzNR1OlR.pdf/ b0e35dbd-f2dc-445d-be0a-2530681d1a67

16. Klein DM, Pham K, Samy L, et al. The veteran-initiated electronic care coordination: a multisite initiative to promote and evaluate consumer-mediated health information exchange. Telemed J E Health. 2017;23(4):264-72.

17. Turvey C, Klein D, Fix G, et al. Blue Button use by patients to access and share health record information using the Department of Veterans Affairs' online patient portal. J Am Med Inform Assoc. 2014;21(4):657-63.

18. Turvey CL, Klein DM, Witry M, et al. Patient education for consumer-mediated HIE. A pilot randomized controlled trial of the Department of Veterans Affairs Blue Button. Appl Clin Inform. 2016;7(3):765-76.

19. US Department of Veterans Affairs, VA Information Resource Center. VIReC research user guide: VHA pharmacy prescription data. 2nd ed. September 2008. Accessed June 29, 2021. https:// hrs.isr.umich.edu/sites/default/files/ restricted data docs/RUG-Pharmacy2nd-Ed-CY08-RA.pdf

20. Murphy PA, Cowper DC, Seppala G, Stroupe KT, Hynes DM. Veterans Health Administration inpatient and outpatient care data: an overview. Eff Clin Pract. 2002;5(3 Suppl):E4.

21. Abrams TE, Vaughan-Sarrazin M, Kaboli PJ. Mortality and revascularization following admission for acute myocardial infarction: implication for rural veterans. J Rural Health. 2010;26(4):310-17.

22. Pope G, Kautter J, Ellis R, et al. Risk adjustment of Medicare capitation payments using the CMS-HCC model. Health Care Financ Rev. 2004;25(4):119-41.

23. Morgan RO, Petersen LA, Hasche JC, et al. VHA pharmacy use in veterans with Medicare drug coverage. Am J Manag Care. 2009;15(3):e1-8. 
24. Zeng F, An JJ, Scully R, Barrington C, Patel BV, Nichol MB. The impact of value-based benefit design on adherence to diabetes medications: a propensity score-weighted difference in difference evaluation. Value Health. 2010;13(6):846-52.

25. Stroupe KT, Smith BM, Bailey L, et al. Medication acquisition by veterans dually eligible for Veterans Affairs and Medicare Part D pharmacy benefits. Am J Health Syst Pharm. 2017;74(3):140-50.

26. Emsley R, Lunt M, Pickles A, Dunn G. Implementing double-robust estimators of casual effects. Stata J. 2008;8(3):334-53.
27. Bouhaddou O, Bennett J, Teal J, et al. Toward a virtual lifetime electronic record: the Department of Veterans Affairs experience with the Nationwide Health Information Network. AMIA Annu Symp Proc. 2012;2012:51-60. Published online November 3, 2012.

28. Byrne CM, Mercincavage LM, Bouhaddou O, et al. The Department of Veterans Affairs' (VA) implementation of the Virtual Lifetime Electronic Record (VLER): findings and lessons learned from Health Information Exchange at 12 sites. Int J Med Inform. 2014;83(8):537-47.

29. Lehnbom EC, Stewart MJ, Manias E, Westbrook JI. Impact of medication reconciliation and review on clinical outcomes. Ann Pharmacother. 2014;48(10):1298-312.
30. Bohnert ASB, Ilgen MA, Galea S, McCarthy JF, Blow FC. Accidental poisoning mortality among patients in the Department of Veterans Affairs Health System. Med Care. 2011;49(4):393-96.

31. Wolinsky FD, An H, Liu L, Miller TR, Rosenthal GE. Exploring the association of dual use of the VHA and Medicare with mortality: separating the contributions of inpatient and outpatient services. BMC Health Serv Res. 2007;7:70.

32. Pizer SD, Gardner JA. Is fragmented financing bad for your health? Inquiry. 2011;48(2):109-22.

33. Jia H, Zheng Y, Reker DM, et al. Multiple system utilization and mortality for veterans with stroke. Stroke. 2007;38(2):355-60. 